Philosophical Papers

\title{
FREGE'S DEFINITION OF NUMBERS
}

\section{Edwin Martin}

To cite this article: Edwin Martin (1987) FREGE'S DEFINITION OF NUMBERS, Philosophical Papers, 16:1, 59-73, DOI: 10.1080/05568648709506266

To link to this article: https://doi.org/10.1080/05568648709506266

进 Published online: 20 Jan 2010.

Submit your article to this journal

Џلll Article views: 8

Q View related articles $\longleftarrow$ 


\title{
FREGE'S DEFINITION OF NUMBERS
}

\author{
Edwin Martin \\ Indiana University
}

In searching for a theory of number, one of the first and most fundamental decisions (or discoveries) to be made for Frege concerns the logical status of numbers: are they objects or functions? The route to the answer to this question in the Grundlagen ${ }^{1}$ is tortuous indeed. It does not immediately emerge that numbers are objects, and given a knowledge of Frege's later work, one might not think that this view was forthcoming at all. In what follows I want to consider just what objects Frege thinks numbers are, and how and why his early account of this in the Grundlagen differs from his later Grundgesetze formulation.

We cannot see numbers as applicable to physical objects, Frege thought, for it is not clear which numbers will apply:

I am able to think of the Iliad either as one poem or as 24 Books, or as some large number of verses . . One pair of boots may be the same visible and tangible phenomenon as two boots. $(F A, 28,33)$

Applications of numbers, rather, must be relative to some standard of counting, some criterion for dividing things up:

The concept 'letters in the word three' isolates the $t$ from the $h$, the $h$ from the $r$, and so on. The concept 'syllables in the word three' picks out the word as a whole, and as indivisible in the sense that no part of it falls any longer under the same concept ... Only a concept which isolates what falls under it in a definite manner, and which does not permit any arbitrary division of it into parts, can be a unit relative to a finite number. $(F A, 66)$

Numbers, then, must primarily apply to a concept, one 'which 
isolates what falls under it in a definite manner.' Frege later became willing to assign numbers to courses-of-values, a kind of object; but this was not a change of view, for with the courseof-values comes a concept which uniquely determines how the relevant objects are to be divided. There is no chance of ambiguity.

Attributions of number, then, are statements about concepts:

If I say 'Venus has $\mathrm{O}$ moons', there simply does not exist any moon or agglomeration of moons for anything to be asserted of; but what happens is that a property is assigned to the concept 'moon of Venus' namely that of including nothing under it. $(F A, 59)$

Now we know that Frege thought of properties of first-level concepts as second-level concepts; and the property of a concept of including nothing under it he expressed in terms of quantifiers - often cited as examples of second-level concept names. A name of the property of a concept of including nothing under it, in a modern notation equivalent to Frege's, is

$$
\text { (1) }(x)-f x
$$

From here it is a small step to thinking of the second-level concept, this property of concepts, as the number 0 . 'Venus has 0 moons' then comes to be construed as: the concept 'moon of Venus' has the property 0 - the property of including nothing under it.

Apparent confirmation of this construal of Frege's words is later to be found. He says,

. . the proposition that there exists no rectangular equilateral rectilinear triangle does state a property of the concept 'rectangular equilateral rectilinear triangle'; it assigns to it the number nought. In this respect existence is analogous to number. Affirmation of existence is in fact nothing but denial of the number nought. $(F A, 64 f)$

And three pages later we find Frege saying "that we have 
learned [that] the content of a statement of number is an assertion about a concept.'

Other non-negative integers, on this construal, would be other second-level concepts. The number 1 , for instance, would be the property of a concept of including exactly one thing under it. A name of this property is readily available for Frege: and we might put it as

$$
(E x)(y)(f(y) \longrightarrow x=y) .
$$

Generally, the number $\mathrm{n}$ would be the property of a concept of including exactly $\mathrm{n}$ things under it. All such properties would find familiar names in Frege's symbolism.

Even though Frege's words suggest that numbers are these second-level concepts, we later find that 'we have already settled that number words are to be understood as standing for self-subsistent objects' $(F A, 73)$. Somewhere, then, in the intervening pages lies the reasoning to this conclusion. Part of that reasoning seems to involve the ease with which adjectival uses of number words can be supplanted by nominal uses. It was precisely the adjectival uses which led us to view numbers as the references of quantifiers. But, Frege thinks, such uses can always be eliminated in favor of nominal uses; thus 'Jupiter has four moons' goes over into 'The number of Jupiter's moons is four' (cf. $F A, 69,116$ ). So what is important is the use of a number word as a noun; it is this Frege attends to in seeking the logical status of numbers.

The rest of Frege's evidence is grammatical. We find him repeatedly emphasizing two sides to a criterion for distinguishing names of objects from concept words. Object names, he insists, are not pluralizable, though concept words are $(F A, 49,50,59,63,64,80)$; and concept words take only the indefinite article, while names of objects never do - they take only the definite article (cf. $F A, 49,63,64,68,77,80$ ). Given this, it is easy to see why Frege glosses numerals as names of objects, and thus thinks numbers to be objects (that is, the references of object names). For, 'the word 'one', as the proper name of an object of mathematical study, does not admit of a plural,' $(F A, 58)$ and 'we speak of 'the number l', where the definite article serves to class it as an object' $(F A, 68)$; or, again, 
When we speak of 'the number one', we indicate by means of the definite article a definite and unique object of scientific study. There are not diverse numbers one, but only one. In 1 we have a proper name, which as such does not admit of a plural any more than 'Frederick the Great' or 'the chemical element gold'. $(F A, 49)$

As Dummett notes ${ }^{2}$ (Frege, 58ff), these criteria are superficial, and adequate conditions for characterizing proper names would no doubt appeal to patterns of valid inference. But what is primary here is not the degree and kind of 'saturation' that 1 might have, but, rather, the role it plays in the hierarchy of reference; that is, we look to the syntactic category of its name 3 . Frege's tests are supposed to be helpful in determining the syntactic categories of expressions, and thus determining where their references fit into the hierarchy of reference. We look to the language, then, to find 'a concept of number usable for the purposes of science'; if we can get the logical grammar of the language straight, then we will be well on our way to seeing what objects and what concepts there are. So Frege determines whether or not something is an object by determining if its names are proper names, and this takes the form of grammatical tests.

How can we reconcile this ultimate conclusion with the other passages? We find, Frege thinks, when we 'get a clearer view of what we mean by our expression 'the content of a statement of number is an assertion about a concept' ' that

in the sentence 'the number 0 belongs to the concept $F$ ', 0 is only an element in the predicate ... For this reason $I$ have avoided calling a number such as 0 or 1 or 2 a property of a concept. Precisely because it forms only an element in what is asserted, the individual number show itself for what it is, a self-subsistent object. $(F A, 68)$

Frege here seems to say that 'The number 0 belongs to the concept $F$ should not be pictured as in (1), but rather as something like ' $\mathrm{N}(\mathrm{F}, 0)$ '; accordingly, a name of the property of a concept of including nothing under it would be, not (1), but ' $\mathrm{N}(\mathrm{f}, 0)$ ', or better, 
$\mathrm{Nx}(\mathrm{f}(\mathrm{x}), 0)$

Numerals, then, form only part of concept words. And since they take definite, not indefinite, articles, and are not pluralizable, they should be seen as proper names in order to serve the 'purposes of science.'

Now Frege believed that all the truths about numbers arithmetical truths -

are analytic judgments and consequently a priori. Arithmetic thus becomes simply a development of logic, and every arithmetical truth a law of logic, albeit a derivative one. $(F A, 99)$

Every arithmetical truth, then, is "deducible solely from purely logical laws.' This thesis by itself does not commit Frege to holding that arithmetic appeals to no irreducibly arithmetical notions, but only that such notions appear vacuously in arithemitical truths and could be systematically supplanted by other notions without affecting deducibility. Frege, however, did hold that arithmetic deals with no irreducibly arithmetical notions; the primitive vocabulary of arithmetic, he thought, is logical in nature and can be defined satisfactorily in logical terms. He thus held that a two-pronged reduction of arithmetic to logic could be made: (a) all arithmetical vocabulary can be defined in purely logical terms, and (b) all arithmetical truths can be proven by purely logical means from a base containing only laws of logic. We know today, thanks to Gödel, that given natural constraints, (b) is false.

As we have seen, Frege took it that concepts were primarily what attributions of number were about and 'that the number studied by arithmetic must be conceived not as a dependent attribute, but substantivally'. $(F A, 116)$ This suggests that a way into the reduction is to define 'the number of Fs' for arbitrary concept F; we might represent this as: NxFx. To accomplish this Frege first said what it is for the objects falling under $F$ and under $G$ to be correlated one-one with each other by the relation $R$. Frege thought of this relation as holding between the courses-of-values of $F$ and of $G$. The course-ofvalues of a concept $F$ (which I will symbolize as 'e' $F e$ ') can, in 
this context, be thought of without much loss as the set of objects falling under $F$. Though this is not quite right, it is a helpful approximation. We can then abbreviate the relation as

$$
1-1 \mathrm{R}\left(\mathrm{e}^{\prime} \mathrm{Fe}, \mathrm{e}^{\prime} \mathrm{Ge}\right)
$$

The definition Frege gave of this is now standard. It involves four things: (i) $\mathrm{R}$ maps Fs only to Gs, (ii) $\mathrm{R}$ maps an $\mathrm{F}$ to each $\mathrm{G}$, (iii) $\mathrm{R}$ is a function, and (iv) $\mathrm{R}$ is one-one (see $F A$, $83 \mathrm{ff}$ ). Next Frege said what it is for the concept $F$ to be equinumerous with the concept $G$; obviously this holds just if there are just as many Fs as Gs, and this holds just if the objects falling under $F$ and those falling under $G$ can be correlated one-one with each other. Thus the stipulation is that

$$
\text { (ER)1-1 R (e'Fe, e'Ge) }
$$

This Frege seems to regard as a second-level relation holding between the concepts $\mathrm{F}$ and $\mathrm{G}$. Thus we might abbreviate it as

$$
\operatorname{EQx}(F x, G x) \text {. }
$$

This now gives us a way to explain the senses of some sentences containing expressions of the form the number of Fs'. In particular, we can explain a sentence such as 'The number of $F s=$ the number of Gs' as meaning, simply, that EQx $(F x, G x)$. But, still, we are not yet in a position to explain the senses of all sentences containing expressions of the form 'the number of Fs'; we have no sense, for example, for 'The number of Fs $=$ Julius Caesar' (see $F A, 117$ ). Nor does it seem that we could declare all such sentences false with-out running the risk of glossing a truth like 'The number of Fs $=2$ ' as false.

The situation here is quite analogous to that of course-ofvalues. ${ }^{4}$ An identity involving two numerical abstracts,

$$
\mathrm{NxFx}=\mathrm{NxGx}
$$

is explained by Frege in terms of a higher-order concept as,

$$
\operatorname{EQx}(F x, G x) \text {. }
$$


Similarly, an identity involving two courses-of-values abstracts,

$$
\mathrm{e}^{\prime} \mathrm{Fe}=\mathrm{e}^{\prime} \mathrm{Ge}
$$

is explained by Frege (by invoking Basic Law V) in terms of a higher-order concept as

$$
(\mathrm{x})(\mathrm{Fx} \leftrightarrow \mathrm{Gx}) \text {. }
$$

Such an explanation is not sufficient in the case of course-ofvalues abstracts to provide for elimination of them from all sentential contexts. First, there are identities involving only one abstract, as in

$$
\mathrm{e}^{\prime} \mathrm{Fe}=(\mathrm{x}) \mathrm{x}=\mathrm{x} \text {. }
$$

Frege deals with these sentences by identifying truth values with certain courses-of-values, thus reducing this case to the first kind. The analogous problem for numerical abstracts is with identities containing only one abstract, as in

$$
\mathrm{NxFx}=\mathrm{a} .
$$

And ' $a$ ' might here be a name of Julius Caesar.

It turns out with course-of-values abstracts that even the added identification of truth values with course-of-values is insufficient for complete elimination. For example, we are still helpless with respect to

$$
\text { (x) } \mathrm{e}^{\prime}(\mathrm{e}=\mathrm{e})=\mathrm{x} \text {. }
$$

Elsewhere I call this a case (1) problem. ${ }^{5}$ Formally identical problems occur for numerical abstracts. Consider the concept 'is the number of the concept F,' viz.,

$$
\mathrm{NxFx}=\mathrm{y} .
$$

Consider now the number of this concept, viz., 
$\operatorname{Ny}(\mathrm{NxFx}=\mathrm{y})$.

And now consider the identity

$\mathrm{Ny}(\mathrm{NxFx}=\mathrm{y})=\mathrm{NyGy}$.

Our reductive equivalence tells us that this last identity means the same thing as

$\operatorname{EQy}(\mathrm{NxFx}=\mathrm{y}, \mathrm{Gy})$,

and expanding this to primitive terms yields a statement of the form

$$
(E R)((y)(N x F x=y \rightarrow(E z) \ldots)
$$

And this is precisely a case (I) problem for numerical abstracts, for we have an abstract on one side of the identity sign and a variable bound by a quantifier on the other side. Of course other problem cases with course-of-values abstracts will be mirrored here as well. So all of the problems with elimination of course-of-values abstracts will also be problems for eliminating numerical abstracts. And since it is quite implausible that all objects will be the number of some concept, chances for solution here are even dimmer than they are with course-of-values.

The way out of these difficulties, Frege thought, is to present an explicit definition of 'the number of Fs' which would render it eliminable from any context. Thus he went on to say what it is to be the number which belongs to the concept $\mathrm{F}-\mathrm{NxFx}$; it is 'the extension of the concept "equinumerous with the concept $F^{\prime}(F A, 85)$, that is

$$
g^{\prime}(\operatorname{EQx}(F x, g x)) \text {. }
$$

The concept 'equinumerous with the concept $F$ ' is secondlevel, applying as it does to first-level concepts; thus its courseof-values is no ordinary one. Frege later talked of courses-ofvalues only for first-level functions and explicitly thought of them this way in the Grundgesetze (see Basic Laws, 87). The 
above definition extricates Frege from his previous difficulties because now every sentence in which 'the number of Fs' occurs can be transformed into a sentence whose sense is known; though we may still not know the truth value of 'The number of $F_{s}=$ Julius Caesar', its sense is determined - it is that of ' $g$ '(EQx $(F x, g x))=$ Julius Caesar'.

Frege can now go on to say that an object is a number just in case it is the number of some concept $(F A, 85)$, i.e.,

$$
\mathrm{N}(\mathrm{a}) \leftrightarrow(\mathrm{Ef}) \mathrm{a}=\mathrm{Nxfx}
$$

0 will be the number of the concept 'not identical with itself', i.e.,

$$
0=\mathbf{N x}(\mathbf{x} \neq \mathbf{x})
$$

Further definitions of the other natural numbers, of succeeding $n$ in the series of natural numbers, addition, multiplication, and so on are now possible. These were to provide a suitable basis for proving Peano's postulates and thus, Frege thought, all arithmetical truths.

Frege's later presentation of his derivation of arithmetic from logic was a little different and, in terms of his mature doctrines about functions, tidier. The number function is the Grundgesetze, unlike Nxfx, is a first-level function which is applicable to objects generally. The number of the course-ofvalues of $F$ now is a certain ordinary course-of-values. If we were to put the differences between the Grundlagen and Grundgesetze accounts in terms of sets, it might be:

the number of the concept $\mathrm{F}$ in the Grundlagen is the set of all equinumerous concepts,

while

the number of the set of Fs in the Grundgesetze is the set of all equinumerous sets.

More accurately, the difference is: 
the number of the concept $\mathrm{F}$ in the Grundlagen is the courseof-values of the concept: is a concept equinumerous with $F$,

while

the number of the course-of-values of the concept $F$ in the Grundgesetze is the course-of-values of the concept: is a course-of-values equinumerous with the course-of-values of the concept $F$.

In the Grundgesetze, accordingly, appeal need only be made to courses-of-values of first-level functions; and, unlike the Grundlagen account, we need only a second-level course-ofvalues function which takes first-level functions to objects. 0 , on the latter account, is simply $\mathrm{e}^{\prime}(\mathrm{e} \neq \mathrm{e})$ (the course-of-values corresponding to the empty set).

The differences in the two series of definitions does not represent a major change in Frege's beliefs about numbers. Rather, it is just a reflection of the maturing of his views of functions during the nine year period. In the Grundlagen Frege did not have a full view of the relations between functions and objects and was thus liable to obscure distinctions and differences he would be at pains to emphasize in the Grundgesetze. Yet the Grundgesetze presents the ideas of the Grundlagen slightly reformed but essentially unchanged. On both accounts, of course, numbers are objects.

We have seen that Frege thought numbers to be objects because he thought numerals satisfy certain grammatical tests for being proper names. These tests Dummett characterizes as 'superficial' and notes that Frege

thus did not adequately protect himself from the gibe that he would be forced to admit such objects as the whereabouts of the prime minister or the manner in which General Eisenhower putts. ${ }^{6}$

Frege's concern with identity conditions might, as Dummett notes, be taken to provide the needed protection: not only must an expression be non-pluralizable and take the definite article if it is to name an object, but it must have a definite sense: 
If we are to use the symbol a to signify an object, we must have a criterion for deciding in all cases whether $b$ is the same as a, even if it is not always in our power to apply this criterion... When we have thus acquired a means of arriving at a determinate number and of recognizing it again as the same, we can assign it a number word as its proper name. $(F A, 73)$

This, Frege maintained, is not to say that the relationship of identity is peculiar to numbers, or that a special kind of identity is especially applicable. Rather, there is one unequivocal relation which holds among all kinds of objects. He says,

We should expect the concept of identity to have been fixed first, and that then, from it together with the concept of Number, it must be possible to deduce when Numbers are identical with one another, without there being need for this purpose of a special definition of numerical identity as well. $(F A, 74)$

We can fix the general relationship of identity à la Leibniz, as Frege does $(F A, 76)$. Given Frege's acceptance of concepts, what is suggested is that $a=b$ if and only if all concepts under which a falls are concepts under which $b$ falls, and vice versa. Indeed, in the Grundgesetze, the truth of this is explicitly asserted (see Basic Laws, \$20, pp. 111, 115) and appears to be taken as a reformulation of the Grundlagen version. But then it is hard to see why this does not provide 'a criterion for deciding .... whether $b$ is the same as a, even if it is not always in our power to apply' it. That is, why does not the relation of identity by itself fix the sense of any proper name by providing a criterion of identity?

If Frege were asked to decide whether the number of planets is Julius Caesar he would no doubt reply that this is just the question of whether Julius Caesar is the extension of the concept: is a concept equinumerous with the concept planet. But, now, how is this question to be decided; what is the relevant criterion of identity? It is just that whatever concept Caesar falls under our extension does also, and conversely? If 
so, it is hard to see that much has been gained. As Dummett says in another connection,

It is not at all clear that [Frege gets] out of the difficulty he believed himself to be in, for in order to use the technique to demonstrate that Julius Caesar is not the number of planets, we have to know that Julius Caesar is not a class of concepts, and the question arises how we know this. ('Frege, Gottlob,'235)

If the criterion is to be one which 'it is not always in our power to apply', then the general criterion of identity seems indispensible and as good as any other. If, though, the criterion is to improve on our abilities of discrimination, then it is not at all clear that Frege succeeds. It seems just false that 'our definition affords us a means of recognizing this object as the same again' in any way not afforded us by the Leibnizian criterion.

Perhaps Frege only means to suggest that all identity sentences must be provided with a clear sense. The only way to do this which will not be circular, will not somewhere appeal to some unexplained proper name, is to start from a base composed wholly of function names. In the Grundgesetze this is done. The Grundlagen account fits well with this approach: it provides senses for all sentences containing an expression of the form 'the number of Fs' in logical terms - provided the other expressions in the sentence are antecedently understood. Of course, these problems, seemingly, would have to be faced all over again with function names.

In the Grundgesetze $(\$ 10)$ Frege faced similar difficulties with courses-of-values, and, as we have seen, he handled them quite differently. The initial problem, analogous to defining 'the number of Fs' ('NxFx'), is to define 'the course-of-values of F' ('e'Fe'). Here the first step is to say when courses-ofvalues are the same: viz.,

$$
\mathrm{e}^{\prime} \mathrm{Fe}=\mathrm{e}^{\prime} \mathrm{Ge} \leftrightarrow(\mathrm{x})(\mathrm{Fx} \leftrightarrow \mathrm{Gx})
$$

The analogous first step with numbers is to say when numbers are the same: viz., 


$$
\mathrm{NxFx}=\mathrm{NxGx} \leftrightarrow \mathrm{EQx}(\mathrm{Fx}, \mathrm{Gx})
$$

It is at this point that Frege began to worry about Julius Caesar and sought an explicit definition of 'the number of Fs'. In the Grundgesetze though, Frege goes to other way with coursesof-values: instead of seeking an explicit definition of "the course-of-values of $F$ ' he tries to give rules for deciding the senses of all sentences in which course-of-values notation appears. He gives, that is, a series of contextual definitions aimed at allowing elimination of course-of-values abstracts from any context. In the formal language of the Grundgesetze truth values are the only available objects besides courses-ofvalues, and so the whole problem seems to boil down to deciding the sense of an identity sentence involving a name of a course-of-values and a name of a truth value: e.g., 'e' $\mathrm{Fe}=$ (Ex)Fx'. In order to attach a definite sense to sentences like this Frege identifies truth values with certain courses-of-values; he is thus able to see the sense of such identity sentences as the same as certain sentences stating identities between courses-ofvalues, and the senses of these have already been explained. (This will, as noted before, leave us powerless to decide the senses of some sentences.) The analogous move when Frege comes to numbers would be to identify courses-of-values (and thus truth values as well) with certain numbers; in a way, Frege does the reverse: he identifies numbers with certain courses-ofvalues. But now all the problems with Julius Caesar and criteria of identity for numbers should disappear because every identity of the arithmetic language will have a definite sense. Had Frege's treatment of numbers paralleled his treatment of courses-of-values, no explicit definitions would have been given. Frege might have readily adopted such a parallel course with numbers had it occurred to him, for he thought that his Grundlagen solution

cannot be expected to meet with universal approval, and many will prefer other methods of removing the doubt in question. I attach no decisive importance even to bringing in the extensions of concepts at all. $(F A, 117)$

The success of Frege's reduction of arithmetic to logic 
depends on there being enough relations of the right kind to correlate the Fs one-one with the Gs whenever, intuitively, there are as many Fs as Gs. It also depends on there being enough variety in relations to guarantee the infinity of the number sequence, to guarantee that every number has an immediate successor in the series. The relevant notions Frege was able to express with the aid of his celebrated definition of the ancestral. First he defines ' $n$ follows in the series of natural numbers directly after $m$ ', $S(m, N)$, as

$$
(E f)(E y)(f y \& N x f x=n) \& N x(f x \& x \neq y)=m) .
$$

(See $F A, 89$ ). Then Frege says what it is for $\mathrm{n}$ to follow $\mathrm{m}$ (directly or indirectly) in the number series, $S^{*}(m, n)$ :

$$
(f)((x)(S(m, x) \rightarrow f x) \&(x)(y)(f x \& S(x, y) \rightarrow f y)) \rightarrow f n) .
$$

(See $F A, 92$ ). Now for each number $\mathrm{n}$ Frege needs a concept under which exactly $n+1$ objects fall; and for this the concept of being a natural number less than or equal to $n$ will serve:

$$
\mathrm{S}^{*}(\mathrm{a}, \mathrm{n}) \text { or } \mathrm{a}=\mathrm{n} \text {. }
$$

This name will be a correctly-formed concept-word of the begriffsschrift and therefore according to Frege it will stand for a concept. Thus included in Frege's 'logic' is the existential assumption that there are infinitely many concepts. Also included is the existential assumption that for each concept, $F$, there is a certain object which is the extension of the concept: is a concept equinumerous with $F$. These two assumptions and other minor ones governing courses-of-values - are enough to guarantee the infinity of the number sequence.

The underlying 'logic' Frege appeals to, then, is not just elementary logic, i.e., quantification theory and theory of identity. It includes, rather, presumptions of the existence of certain concepts and extensions. It is comparable, therefore, to set theory or second-order logic; it is set theory in sheep's clothing, but set theory nonetheless. Consequently it seems plausible that Frege's construal of logic is somewhat wider than that of his predecessors, and that, as Quine says, 
Kant's readiness to see logic as analytic and arithmetic as synthetic . . . is not superseded by Frege's work (as Frege supposed) if 'logic' be taken as elementary logic. And for Kant logic certainly did not include set theory.?

Kant, that is, very well might not have seen Frege's reductions of arithmetical truths as flowing solely by logic from purely logical laws: he could well have seen Frege existential assumptions, though true, as surpassing the laws of logic.

The inconsistency Russell found in the Grundgesetze, of course, is a result of Frege's assumptions about the existence of concepts and extensions. Elimination of the assumptions, or Frege's alteration of them, has a disasterous effect on Frege's reduction: as Frege was quick to notice, all but a handful of his proofs depend upon them and thus will be invalidated. This is an undeniably fatal blow to Frege's claim to have shown arithmetic analytic. Still, Frege's work paved the way for construction of set theories which are not known to be inconsistent and within which Peano's postulates and consequent arithmetical truths can be derived.

\section{NOTES}

1. Gotlob Frege, Die Grundlagen der Arithmetik (Breslan, W. Koebner, 1884). This is translated as The Foundations of Arithmetic (translated by J.L. Austin; Evanston, Norhtwestern University Press, 1968). This is henceforth cited as $F A$ with page numbers.

2. Michael Dummett, Frege: Philosophy of Language (New York, Harper \& Row, 1973), pp. 58ff.

3. See my 'Fregean Incompleteness', Philosophia, Vol. 13 (1883), pp. 247-253.

4. See Frege, Die Grundgesetze der Arithmetik. Vol. I (Jena, H. Pohle, 1983). This has been translated as The Basic Laws of Arithmetic (Edited and translated by Montgomery Furth; Berkeley, University of California Press, 1964).

5. See my 'Referentiality in Frege's Grundgesetze', History and Philosophy of Logic. Vol. 3 (1982), pp. 151-164.

6. Michael Dummett, 'Frege, Gottlob', Encyclopedia of Philosophy (Edited by Paul Edwards; New York, Macmillan, 1967), Vol. 2. pp. 225-237. See too his Frege. pp. $70 \mathrm{ff}$.

7. W.V. Quine, The Ways of Paradox (New York, Random House, 1966), p. 104. 